Polymer Journal, Vol. 6, No. 1, pp 7-11 (1974)

\title{
ESR Studies on Primary Processes in Radiation-Induced Reactions. VI. Isoprene and 1,3-Pentadiene in Alkyl Halide Matrices
}

\author{
Tetsuo Shiga and Seizo OKamura \\ Department of Polymer Chemistry, Kyoto University, \\ Kyoto, 606, Japan.
}

(Received January 4, 1973)

\begin{abstract}
The cation radical of isoprene was first detected by means of ESR. It was produced by $\gamma$-irradiation in carbon tetrachloride, and has proton coupling constants of $a_{1}=13.0 \mathrm{G}(2 \mathrm{H}), a_{2}=4.9 \mathrm{G}(3 \mathrm{H}), a_{3}=3.2 \mathrm{G}(1 \mathrm{H})$, and $a_{4}=9.2 \mathrm{G}(2 \mathrm{H})$. In $n$-butyl chloride glass at $77^{\circ} \mathrm{K}$ a linear allyl-type radical was formed from isoprene. The initiation of polymerization by the isoprene cation radical was suggested in $n$-butyl chloride glass at $77^{\circ} \mathrm{K}$ during $\gamma$-irradiation. A cyclohexadienyl-type radical was produced from trans-1,3-pentadiene by $\gamma$-irradiation in carbon tetrachloride, whereas, a linear allyl-type radical was produced from cis-1,3-pentadiene. In a $n$-butyl chloride glass, a linear allyl-type radical was produced from both 1,3 -pentadiene by $\gamma$-irradiation at $77^{\circ} \mathrm{K}$. The cation radical were suggested to initiate radiation-induced polymerization in $n$-butyl chloride glass at $77^{\circ} \mathrm{K}$.
\end{abstract}

KEY WORDS ESR / $\gamma$-Irradiation / Isoprene / 1,3-Pentadiene / Cation Radical / Cyclohexadienyl-Type Radical / Allyl-Type Radical / $n$-Butyl Chloride Glass / Carbon Tetrachloride /

The anion radical of 1,3-butadiene and its derivatives formed by $\gamma$-irradiation were first detected by means of ESR in 2-methyl(tetrahydrofuran) glass at $77^{\circ} \mathrm{K} .^{1}$ The cation radical of 1,3-butadiene was first observed by means of ESR following $\gamma$-irradiation on silica gel. ${ }^{2}$ In this system the butadiene cation radical reacts further with butadiene molecules and produces the allyl-type radical (RI), $\mathrm{CH}_{2}=\mathrm{CH}-\dot{\mathrm{C}} \mathrm{H}-$ $\mathrm{CH}_{2}$-. The alkyl halides are well known as solvents and matrices suitable for studying cationic reactions. In a carbon tetrachloride polycrystalline matrix, the butadiene cation radical has been detected by means of ESR following $\gamma$-irradiation. ${ }^{1} \quad$ In a $n$-butyl chloride glass matrix, the radical $\mathrm{RI}$ is produced from 1,3-butadiene by $\gamma$-irradiation. Thus, it has been suggested that the butadiene cation radical initiates radiation-induced polymerization of 1,3-butadiene in a $n$-butyl chloride glass matrix at $77^{\circ} \mathrm{K}^{1}$ In the present study isoprene and 1,3-pentadiene are investigated in order to elucidate the primary processes of radiationinduced cationic reactions of these dienes by using carbon tetrachloride and $n$-butyl chloride as matrices. It is also intended to detect the ESR spectra of the cation radicals of these dienes and to determine the coupling constants for them, because none of them has been reported yet.

\section{EXPERIMENTAL}

Alkyl halides were purified by distillation, then dried by storing on a molecular sieve $3 \mathrm{~A}$ which has previously been baked at $350^{\circ} \mathrm{C}$ for $8 \mathrm{hr}$ under a pressure of $10^{-5}$ torr. Isoprene, trans-1,3-pentadiene, and cis-1,3-pentadiene were distilled in a vacuum line. Samples were prepared by adding known amounts of diene to a solvent in a vacuum line, then sealed off under a pressure of $10^{-5}$ torr. Irradiation was carried out at $77^{\circ} \mathrm{K}$ with a ${ }^{60} \mathrm{Co} \gamma$-source at a dose rate of $2 \mathrm{Mrad} / \mathrm{hr}$ to a total dose of $1 \mathrm{Mrad}$. ESR measurements were made with a Varian E-3 $\mathrm{X}$-band spectrometer with $100-\mathrm{kHz}$ magnetic field modulation at a microwave power of $2 \mathrm{~mW}$. This microwave power is the best 
condition for ESR measurements with the presently used spectrometer. The lineshape of the spectrum is not distored by this microwave power.

\section{RESULTS}

\section{Carbon Tetrachloride Matrix}

The ESR spectrum at $77^{\circ} \mathrm{K}$ is seriously masked

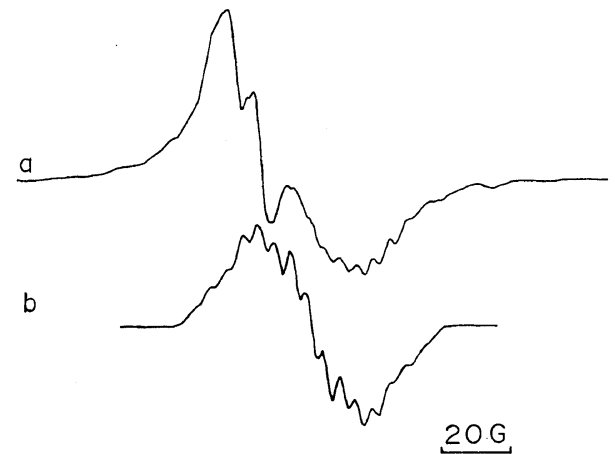

Figure 1. ESR spectra in carbon tetrachloride polycrystal following $\gamma$-irradiation at $77^{\circ} \mathrm{K}$, measured at $163^{\circ} \mathrm{K}$ : a, $1.5 \mathrm{~mol} \%$ of isoprene; $b$, computed spectrum using the parameters, $a_{1}=$ $13.0 \mathrm{G}(2 \mathrm{H}), a_{2}=4.9 \mathrm{G}(3 \mathrm{H}), a_{3}=3.2 \mathrm{G}(1 \mathrm{H}), a_{4}=$ $9.2 \mathrm{G}(2 \mathrm{H})$, and a Gaussian linewidth of $4.5 \mathrm{G}$.

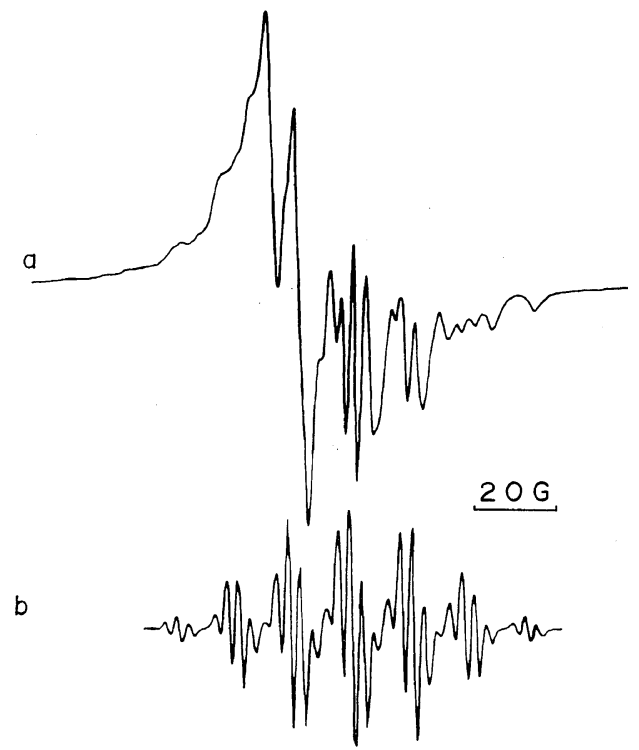

Figure 2. ESR spectra in carbon tetrachloride polycrystal following $\gamma$-irradiation at $77^{\circ} \mathrm{K}$, measured at $120^{\circ} \mathrm{K}$ : a, $1.0 \mathrm{~mol} \%$ of trans-1,3-pentadiene; $\mathrm{b}$, computed spectrum using the parameters, $a_{1}=$ $48.5 \mathrm{G}(4 \mathrm{H}), a_{2}=8.6 \mathrm{G}(4 \mathrm{H}), a_{3}=2.8 \mathrm{G}(2 \mathrm{H})$, and $\mathrm{a}$ Gaussian linewidth of $3.5 \mathrm{G}$.


Fugure 3. ESR spectra in carbon tetrachloride polycrystal following $\gamma$-irradiation at $77^{\circ} \mathrm{K}$, measured at $163^{\circ} \mathrm{K}$ : a, $1.0 \mathrm{~mol} \%$ of cis-1,3-pentadiene; $\mathrm{b}$, computed spectrum using the parameters, $a_{1}=$ $12 \mathrm{G}(2 \mathrm{H}), a_{2}=15 \mathrm{G}(3 \mathrm{H}), a_{3}=14 \mathrm{G}(1 \mathrm{H}), a_{4}=2.7 \mathrm{G}$ $(2 \mathrm{H})$, and a Gaussian linewidth of $1.5 \mathrm{G}$.

by the signal originating from the carbon tetrachloride. This signal could be partly removed by heating a sample, then the signal from the dienes was observed. The spectrum on a low half field is still superimposed with the signal originating from the matrix with larger $g$ factor, $\dot{\mathrm{CCl}}{ }_{3}{ }^{3}$

The spectrum from $1.5 \mathrm{~mol} \%$ of isoprene at $163^{\circ} \mathrm{K}$ is shown in Figure 1a. The spectrum from $1 \mathrm{~mol} \%$ of trans-1,3-pentadiene at $120^{\circ} \mathrm{K}$ is presented in Figure 2a, and that corresponding to cis-1,3-pentadiene at $163^{\circ} \mathrm{K}$ in Figure 3a. The spectrum in Figure 2a consists of the quintet spectrum with coupling constant of $48.5 \mathrm{G}$.

\section{n-Butyl Chloride Glass Matrix}

The spectra at $77^{\circ} \mathrm{K}$ from $1 \mathrm{~mol} \%$ of isoprene, trans-1,3-pentadiene, and cis-1,3-pentadiene are shown in Figures 4, 5a, and 5b respectively. They appear similar to the spectrum from 1,3butadiene. $^{1}$ The subtraction of the spectrum 


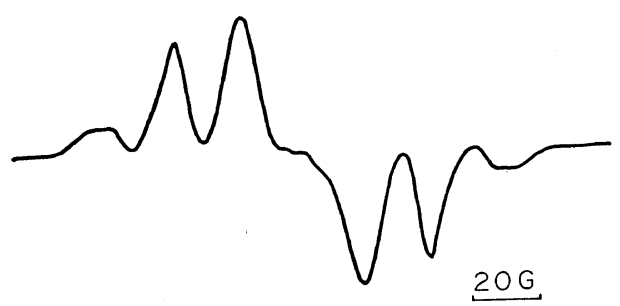

Fugure 4. ESR spectrum of isoprene $1 \mathrm{~mol} \%$ in n-butyl chloride glass matrix measured at $77^{\circ} \mathrm{K}$ following $\gamma$-irradiation at $77^{\circ} \mathrm{K}$.



$\underline{20 G}$

Figure 5. ESR spectra of 1,3-pentadiene in $n$ butyl chloride glass matrix measured at $77^{\circ} \mathrm{K}$ following $\gamma$-irradiation at $77^{\circ} \mathrm{K}$ : a, $1 \mathrm{~mol} \%$ of trans-pentadiene (-), n-butyl radical (---); b, $1 \mathrm{~mol} \%$ of cis-pentadiene.

of the $n$-butyl radical (dotted line in Figure 5a) as a background spectrum from Figures 4 and 5 gives the signals from isoprene, trans-1,3pentadiene, and cis-1,3-pentadiene respectively. Due to a large linewidth of the spectra it is difficult to judge whether the spectra obtained after subtraction procedure are quintet or septet spectra. However, it is clear that their peaks are separated by about $15 \mathrm{G}$, and that they do not contain the coupling constant of $48.5 \mathrm{G}$ which is observed in trans-1,3-pentadiene in carbon tetrachloride (Figure 2a).

\section{DISCUSSION}

The analysis of the spectra which are superimposed on the signal originating from carbon tetrachloride on a low half field is attempted on the spectra on a high half field. The simulation spectrum for Figure $1 \mathrm{a}$ is obtained by using parameters of $a_{1}=13.0 \mathrm{G}(2 \mathrm{H}), a_{2}=4.9 \mathrm{G}$
Table I. Spin densities and proton coupling constants of the isoprene cation radical

\begin{tabular}{|c|c|c|c|}
\hline & $\begin{array}{l}\mathrm{CH}_{3} \\
\mid \stackrel{\mathrm{C}}{\mid}-\mathrm{C}-\mathrm{C}\end{array}$ & \multicolumn{2}{|c|}{$a_{\mathrm{H}}(\mathrm{G})$} \\
\hline $\mathrm{C}_{i}$ & Spin density & Calcd ${ }^{a}$. & Obsd. \\
\hline 1 & 0.391 & 11.5 & 13.0 \\
\hline 2 & 0.136 & - & - \\
\hline 3 & 0.112 & 3.2 & 3.2 \\
\hline 4 & 0.322 & 9.2 & 9.2 \\
\hline $\mathrm{CH}_{3}$ & & $7.7^{\mathrm{b}}$ & 4.9 \\
\hline
\end{tabular}

a Calculated with the formulae in ref 3.

b Calculated with the formula in ref 4 .

$(3 \mathrm{H}), a_{3}=3.2 \mathrm{G}(1 \mathrm{H}), a_{4}=9.2 \mathrm{G}(2 \mathrm{H})$, and a Gaussian linewidth of $4.5 \mathrm{G}$. Possible radical structures which have 8 protons are the cation radical of isoprene or the allyl-type radical, $\mathrm{CH}_{2}=\mathrm{C}\left(\mathrm{CH}_{3}\right)-\dot{\mathrm{CH}}-\mathrm{CH}_{2}$-, which is the same type of radical as observed in 1,3-butadiene, (RI). In the case of the allyl-type radical, $a_{4}=$ $9.2 \mathrm{G}$ is too small for the coupling constant. The spin densities on carbons of the isoprene cation radical are listed in Table I, which are obtained by Hückel method including a hyperconjugation for the methyl group. The coupling constants expected from the spin densities are obtained by the formulae given by Snyder and Amos $^{4}$ which have predicted fairly well the coupling constants of the cation radical of 1,3butadiene. $^{2}$ The coupling constants of the methyl protons are obtained by the formula given by Levy. ${ }^{5}$ The agreement of the calculated coupling constants for protons on $\mathrm{C}_{1}-\mathrm{C}_{4}$ with those of experimentally obtained coupling constants is good. Therefore, the spectrum presented in Figure 1 is assigned to the isoprene cation radical. The formula given by Levy does not predict the coupling constant of the methyl protons of the isoprene cation radical. The other small peak at a higher field than the simulation spectrum is a part of the signal originating from the matrix.

The simulated spectrum (Figure $2 b$ ) for the spectrum from trans-1,3-pentadiene gives coupling constants of $a_{1}=48.5 \mathrm{G}(4 \mathrm{H}), a_{2}=8.6 \mathrm{G}(4 \mathrm{H})$, $a_{3}=2.8 \mathrm{G}(2 \mathrm{H})$, and a Gaussian linewidth of $3.5 \mathrm{G}$. The coupling constants of $47.71 \mathrm{G}, 8.99 \mathrm{G}$, 
Table II. Calculated spin densities and proton coupling constants of 1,3-pentadiene anion radical

\begin{tabular}{lcc}
\hline \multicolumn{2}{c}{$\mathrm{C}-\mathrm{C}-\mathrm{C}-\mathrm{C}-\mathrm{CH}_{3}$} & \\
& \multicolumn{2}{c}{$a_{\mathrm{H}}, \mathrm{G}^{\mathrm{a}}$} \\
\hline $\mathrm{C}_{i}$ & Spin density & \\
\hline 1 & 0.344 & 9.9 \\
2 & 0.105 & 2.9 \\
3 & 0.165 & 4.8 \\
4 & 0.303 & 8.2 \\
$\mathrm{CH}_{3}$ & & $16.4^{\mathrm{b}}$ \\
\hline
\end{tabular}

a Calculated with the formulae in ref 3 .

b Calculated with the formula in ref 4 .

$2.65 \mathrm{G}$ and $13.04 \mathrm{G}$ have been reported for the cyclohexadienyl radical. ${ }^{6}$ Thus, the coupling constants estimated from Figure 2 indicate reasonably well that the cyclohexadienyl-type of radical is produced in a carbon tetrachloride matrix. The spectrum in Figure $2 \mathrm{a}$ is assigned to

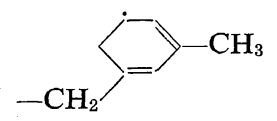

The reaction mechanism for the formation of this radical is not clear. As a possible mechanism cyclic dimerization or further reactions could be considered followed by the abstraction of hydrogen:

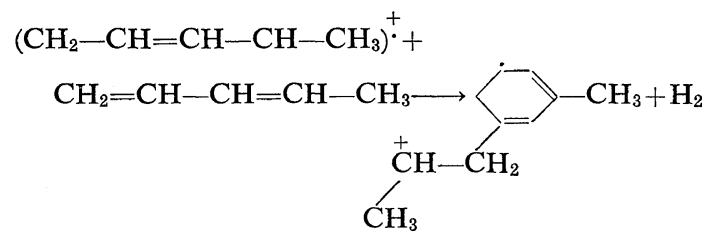

The computed spectrum in Figure $3 b$ is obtained by using parameters of $a_{1}=12 \mathrm{G}(2 \mathrm{H})$, $a_{2}=15 \mathrm{G}(3 \mathrm{H}), a_{3}=14 \mathrm{G}(1 \mathrm{H}), a_{4}=2.7 \mathrm{G}(2 \mathrm{H})$, and a Gaussian linewidth of $15 \mathrm{G}$. The spin densities on carbon atoms and proton coupling constants which are expected for the cation radical of 1,3-pentadiene are listed in Table II. The spin densities are calculated by the Hückel method including hyperconjugation for the methyl group. The coupling constants are calculated by the formulae given by Snyder and Amos $^{4}$ for protons on $\mathrm{C}_{1}-\mathrm{C}_{4}$, and by the formula given by $\mathrm{Levy}^{5}$ for the methyl protons. The estimated coupling constants from Figure 3 are too large for those of the protons on $\mathrm{C}_{1}$ $\mathrm{C}_{4}$ of the 1,3-pentadiene cation radical. The spectrum in Figure $3 \mathrm{a}$ is more reasonably assigned to the allyl-type radical, $\mathrm{CH}_{3}-\dot{\mathrm{C}} \mathrm{H}-$ $\mathrm{CH}=\mathrm{CH}-\mathrm{CH}_{2}-$. In this radical one of the two $\beta$ protons would have the small coupling of $2.7 \mathrm{G}$ and another a similar value to that of the $\alpha$ proton. These coupling constants resemble those of the radical RI from 1,3-butadiene in $n$-butyl chloride and hydrocarbon glass matrices. ${ }^{1}$ The reaction mechanism would be as follows using the analogy of 1,3-butadiene in n-butyl chloride glass.

$$
\begin{aligned}
& \left(\mathrm{CH}_{3}-\mathrm{CH}-\mathrm{CH}=\mathrm{CH}-\mathrm{CH}_{2}\right)^{+}+ \\
& \mathrm{CH}_{2}=\mathrm{CH}-\mathrm{CH}=\mathrm{CH}-\mathrm{CH}_{3}- \\
& \mathrm{CH}_{3}-\dot{\mathrm{C}} \mathrm{H}-\mathrm{CH}=\mathrm{CH}-\mathrm{CH}_{2}-\mathrm{CH}_{2}- \\
& \mathrm{CH}=\mathrm{CH}-\stackrel{+}{\mathrm{C}} \mathrm{H}-\mathrm{CH}_{3}
\end{aligned}
$$

The signals from isoprene, trans-, and cis1,3 -pentadiene in $n$-butyl chloride glass are quintet or septet lines which are separated by about $15 \mathrm{G}$. They are reasonably assigned to the allyl-type radicals in which one of the two $\beta$ protons has a small coupling constant less than a linewidth and another has a similar coupling to the $\alpha$ proton. These couplings of $\beta$ protons are common to the allyl-type radicals from 1,3-butadiene, isoprene and 1,3-pentadiene in organic glass matrices. The magnitude of the $\beta$ proton coupling is approximated to $a_{\beta}=B \cos ^{2} \theta$, whereas $B$ is $45-50 \mathrm{G}$ and $\theta$ is the angle between the axis of the unpaired electron in its $2 p_{z}$ orbital and the projection of the $\mathrm{C}_{\beta}-\mathrm{H}$ bond on a plane orthogonal to the $\mathrm{C}_{\alpha}-$ $\mathrm{C}_{\beta}$ bond. ${ }^{7}$ From this relation the angle is estimated to have the values of about $45^{\circ}$ and $75^{\circ}$.
Isoprene

$$
\begin{aligned}
& \mathrm{CH}_{2}=\mathrm{C}\left(\mathrm{CH}_{3}\right)-\dot{\mathrm{C}} \mathrm{H}-\mathrm{CH}_{2}- \\
& \mathrm{CH}_{2}=\mathrm{CH}-\dot{\mathrm{C}}\left(\mathrm{CH}_{3}\right)-\mathrm{CH}_{2}-
\end{aligned}
$$

quintet

septet
Pentadiene

$$
\begin{aligned}
& \mathrm{CH}_{2}=\mathrm{CH}-\dot{\mathrm{C}} \mathrm{H}-\mathrm{CH}\left(\mathrm{CH}_{3}\right)- \\
& \mathrm{CH}_{3}-\mathrm{CH}=\mathrm{CH}-\dot{\mathrm{C}} \mathrm{H}-\mathrm{CH}_{2}-
\end{aligned}
$$


The cation radicals of isoprene and 1,3pentadiene would be more reactive at 1 position than at 4 position, when the reactivity could be predicted by the Frontier electron density. ${ }^{8}$ If this is the case here, septet lines would be expected from the addition of the cation radicals of these dienes to the corresponding molecules. The initiation mechanism of the radiation-induced polymerization is analogic for 1,3-butadiene, isoprene, and 1,3-pentadiene in $n$-butyl chloride glass matrix at $77^{\circ} \mathrm{K}$.

Several differences between carbon tetrachloride and $n$-butyl chloride matrices, i.e., rigidity, ability for stabilizing the cation radical, monomer distribution and radical species formed from matrices could contribute to the observation of the isoprene cation radical in carbon tetrachloride and the allyl-type radical in $n$-butyl chloride at $77^{\circ} \mathrm{K}$.

The formation of the cyclohexadienyl-type radical from trans-1,3-pentadiene and the linear allyl-type radical from cis-1,3-pentadiene in carbon tetrachloride suggests that these pentadienes have certain differences in their distribution in the matrix which leads to the different reaction mechanisms for trans- and cis-pentadienes in this matrix. On the other hand, in organic glass matrices, both pentadienes are probably distributed in such a way as to form the linear allyl-type radical.
Acknowledgment. The authors are grateful to Professor H. Yamaoka for his encouragement. They wish to express their thanks to the staff of Radiation Chemistry Group in Research Reactor Institute for providing the $\gamma$-source and the ESR spectrometer.

\section{REFERENCES}

1. T. Shiga, A. Lund, and P. O. Kinell, Acta Chem. Scand., 29, 383 (1972); T. Shiga and S. Okamura, Abstract, 15th Discussion Meeting of Japanese Society of Radiation Chemistry, Osaka, October 30, 1972, p 64.

2. T. Shiga, A. Lund, and P. O. Kinell, Int. J. Radiat. Phys. Chem., 3, 131 (1971); T. Shiga, A. Lund, and P. O. Kinell, Acta Chem. Scand., 25, 1508 (1971).

3. J. Sohma, H. Kashiwabara, T. Komatsu, and T. Takahashi, Hokkaido Univ. Kogakubu Kenkyu Hohkoku, 35, 511 (1964).

4. L. C. Snyder and T. Amos, J. Chem. Phys., 42, 3670 (1965).

5. D. H. Levy, Mol. Phys., 9, 233 (1966).

6. S. Ohnishi, T. Tanei, and I. Nitta, J. Chem. Phys., 37, 2402 (1962).

7. C. Heller and H. M. McConnell, ibid., 32, 1535 (1960).

8. T. Yonezawa, Ed., "Ryōshi Kagaku Nyumon", 3rd ed., Kagakudojin, Kyoto, 1969, p 218. 